\title{
PEMANFAATAN FLYWHEEL MAGNET SEPEDA MOTOR DENGAN 8 RUMAH BELITAN SEBAGAI GENERATOR PADA PEMBANGKIT LISTRIK TENAGA MIKROHIDRO
}

\author{
Ari Wijayanto, Hasyim Asy'ari, Agus Supardi \\ Jurusan Teknik Elektro Fakultas Teknik, Universitas Muhammadiyah Surakarta \\ Jl. A. Yani tromol pos 1 pabelan kartasura surakarta \\ wijay67@gmail.com
}

\begin{abstract}
ABSTRAKSI
Listrik merupakan salah satu kebutuhan primer untuk kehidupan manusia sehingga diperlukan suatu pembangkit tenaga listrik. Pembuatan pembangkit listrik tenaga mikrohidro ini bertujuan untuk mengetahui daya keluaran yang mampu dihasilkan oleh flywheel magnet sepeda motor yang dilakukan pengujian di Waduk Botok, Mojodoyong, Kedawung, Sragen, Jawa Tengah dan sekaligus memanfaatan energi terbarukan secara optimal terutama air.

Pemanfaatan aliran sungai di Waduk Botok untuk Pembangkit Listrik Tenaga Mikrohidro ini menggunakan kincir air tipe overshot. Desain kincir air dibuat sedemikian rupa agar dapat memutar flywheel magnet secara maksimal, karena kincir air digunakan sebagai penggerak awal. Sistem pembangkit ini memanfaatkan flywheel magnet sepeda motor sebagai pembangkit listrik, kemudian diubah menggunakai inverter, sehingga menghasilkan keluaran tegangan AC.

Daya yang dihasilkan flywheel magnet dengan debit air sebesar 0,017016 ( $\left.\mathrm{m}^{3} / \mathrm{s}\right)$ dengan kecepatan air $3 \mathrm{~m} / \mathrm{s}$ mampu memutar flywheel magnet asli dan flywheel magnet modifikasi dengan kecepatan putar flywheel magnet rata-rata $750 \mathrm{rpm}$. Daya DC yang dihasilkan flywheel magnet saat dipasang beban lampu maksimal 22 watt flywheel magnet asli menghasilkan daya DC sebesar 12,8 watt dan flywheel magnet modifikasi sebesar 12,4 watt, sedangkan daya AC yang dihasilkan flywheel magnet saat dipasang beban lampu maksimal 22 watt flywheel magnet asli mampu menghasilkan daya AC sebesar 11,3 watt dan flywheel magnet modifikasi sebesar 11,9 watt.
\end{abstract}

Kata kunci: Waduk, PLTMh, flywheel magnet, kincir air

\section{Pendahuluan}

Listrik merupakan salah satu kebutuhan primer untuk kehidupan manusia sehingga diperlukan suatu pembangkit tenaga listrik. Kebutuhan energi listrik yang terus meningkat, maka diperlukan waktu yang tidak sedikit untuk membangun suatu pembangkit tenaga listrik. Diperlukan adanya sumber energi alternatif untuk mengatasi kelangkaan energi. Sumber daya listrik alternatif yang dapat dikembangkan berupa pemanfaatkan potensi air. Pembangkit Listrik Tenaga Mikrohidro (PLTMh) adalah suatu pembangkit listrik skala kecil yang menggunakan tenaga air sebagai tenaga penggeraknya, dengan cara memanfaatkan tinggi terjunan (head) dan jumlah debit air.
Daerah pegunungan memiliki potensi energi listrik yang besar dalam bentuk air.

Sebagian daerah pegunungan terdapat sumber mata air yang mengalir melalui sungai-sungai. Ketinggian aliran sungai tersebut dapat dimanfaatkan sebagai PLTMh. Pada dasarnya, PLTMh memanfaatkan energi potensial jatuhan air (head). Semakin tinggi jatuhan air maka semakin besar energi potensial yang dapat diubah menjadi energi listrik. Mikrohidro bisa memanfaatkan ketinggian air yang tidak terlalu besar, misalnya dengan ketinggian air 2,5 meter.

Pengembangan PLTMh cocok untuk daerah terpencil atau pedesaan yang pada umumnya masih banyak terdapat sumber daya air terutama daerah yang masih banyak 
ditumbuhi pepohonan. Pembangunan PLTMh ditujukan untuk daerah-daerah pedesaan yang memiliki potensi, dari potensi itu hanya dimanfaatkan energinya atau diambil energi potensialnya, tidak banyak mempengaruhi lingkungan atau mengurangi air untuk keperluan pertanian.

Aliran air merupakan salah satu sumber penggerak yang bisa menggerakkan kincir air, flywheel magnet bisa dimanfaatkan pada Pembangkit Listrik Tenaga Mikrohidro. Flywheel magnet mampu menghasilkan putaran yang menghasilkan energi listrik, sehingga dapat digunakan sebagai energi alternatif kedepannya.

Upaya membangun Pembangkit Listrik Tenaga Mikrohidro (PLTMh) adalah upaya untuk mengajak masyarakat hidup bersih dan peduli terhadap lingkungan sekitar. Berdasarkan uraian tersebut, peneliti melakukan penelitian tentang Pembangkit Listrik Tenaga Mikrohidro yang memanfaatkan energi aliran sungai di Waduk Botok dan flywheel magnet sepeda motor sebagai sumber pembangkit listrik.

\section{Metode Penelitian}

\subsection{Jadwal Penelitian}

Penelitian dengan judul pemanfaatan flywheel magnet sepeda motor dengan 8 rumah belitan sebagai generator pada pembangkit listrik tenaga mikrohidro dimulai dari studi literatur, pembuatan proposal sampai analisa data dan pembuatan kesimpulan.

Alur dalam penelitian ini adalah :

a. Studi Literatur

b. Kajian penulis tentang referensi-referensi yang berkaitan dengan penelitian ini berupa buku, skripsi, jurnal publikasi, tesis dan karya ilmiah tentang Pembangkit Listrik Tenaga Mikrohidro (PLTMh).

c. Perizinan di Waduk Botok

d. Mengajukan surat izin kepada petugas penjaga di Waduk Botok, Mojodoyong, Kedawung, Sragen.

e. Pengambilan Data

Penelitian untuk Pembangkit Listrik Tenaga Mikrohidro (PLTMh) menggunakan kincir tipe overshot di Waduk Botok, Mojodoyong,
Kedawung, Sragen. Data yang harus dicatat antara lain :

a. Kecepatan putar flywheel magnet

b. Tegangan dan arus yang dihasilkan flywheel magnet

c. Tahap Pengolahan Data

d. Langkah-langkah yang akan dilakukan sebagai berikut :

e. Merancang rangka besi alat pembangkit.

f. Merancang dudukan generator (flywheel magnet), kincir air dan memasang $v$-belt.

g. Menguji dan mengukur keluaran daya dari generator (flywheel magnet).

h. Menganalisis hasil dari pengujian alat.

i. Membuat kesimpulan dengan melihat hasil dari pengujian yang telah dilakukan.

\subsection{Alat}

Peralatan yang digunakan dalam penelitian ini adalah :

a. Multimeter dan tang ampere (clamp ampere untuk mengetahui arus dan tegangan

b.Tachometer untuk mengukur kecepatan putar flywheel magnet.

c. Laptop digunakan untuk pengoperasian data dan pembuatan laporan.

\subsection{Bahan}

a. Bahan-bahan yang digunakan dalam penelitian ini adalah :

$b$. Pipa PVC dengan diameter $8,5 \mathrm{~cm}$.

c. Besi As,

d. V-Belt A-54

e. Puli dengan perbandingan 2:13

$f$. Kincir air

g. Regulator (kiprok),

h. Inverter

i. Stop kontak dan lampu AC

j. Flywheel magnet

Tabel 1. Klasifikasi flywheel magnet

\begin{tabular}{llll}
\hline $\begin{array}{l}\text { Flywheel } \\
\text { magnet }\end{array}$ & $\begin{array}{l}\text { Jumlah } \\
\text { Rumah } \\
\text { belitan }\end{array}$ & $\begin{array}{l}\text { Diameter } \\
\text { kawat email } \\
(\mathrm{mm})\end{array}$ & $\begin{array}{l}\text { Jumlah } \\
\text { lilitan }\end{array}$ \\
\hline Asli & 8 & 1 & 480 \\
Modifikasi & 8 & 0.9 & 768 \\
\hline
\end{tabular}




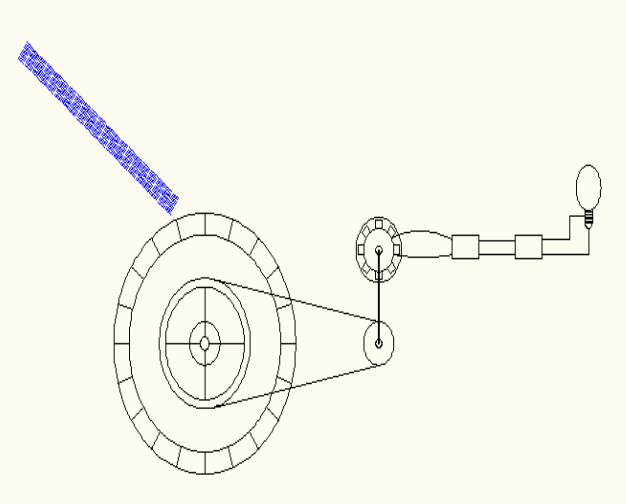

Gambar 1. Bagan pengujian alat

\subsection{Diagram Alur Penelitian}

Penelitian diawali dengan pembuatan alat dimulai dari pembuatan kincir air, pemasangan puli pada poros kincir dan flywheel magnet. Ampere meter, volt meter, inverter di pasang pada rangka besi. Poros pada kincir dan flywheel magnet di pasang puli dengan perbandingan 2:13 dan dihubungkan menggunakan $V$-Belt. Kemudian dari flywheel magnet dihubungkan ke regulator (kiprok), dari regulator dihubungkan ke ampere dan volt meter yang digunakan untuk mengetahui arus dan tegangan DC yang dihasilkan oleh flywheel magnet. Kemudian dihubungkan dengan inverter untuk mengubah tegangan $\mathrm{DC}$ menjadi $\mathrm{AC}$, bagan tersebut ditunjukan pada gambar 1 .

Pengambilan data berupa kecepatan putar, tegangan dan arus flywheel magnet. Flowchart penelitian ditunjukkan pada gambar 2.

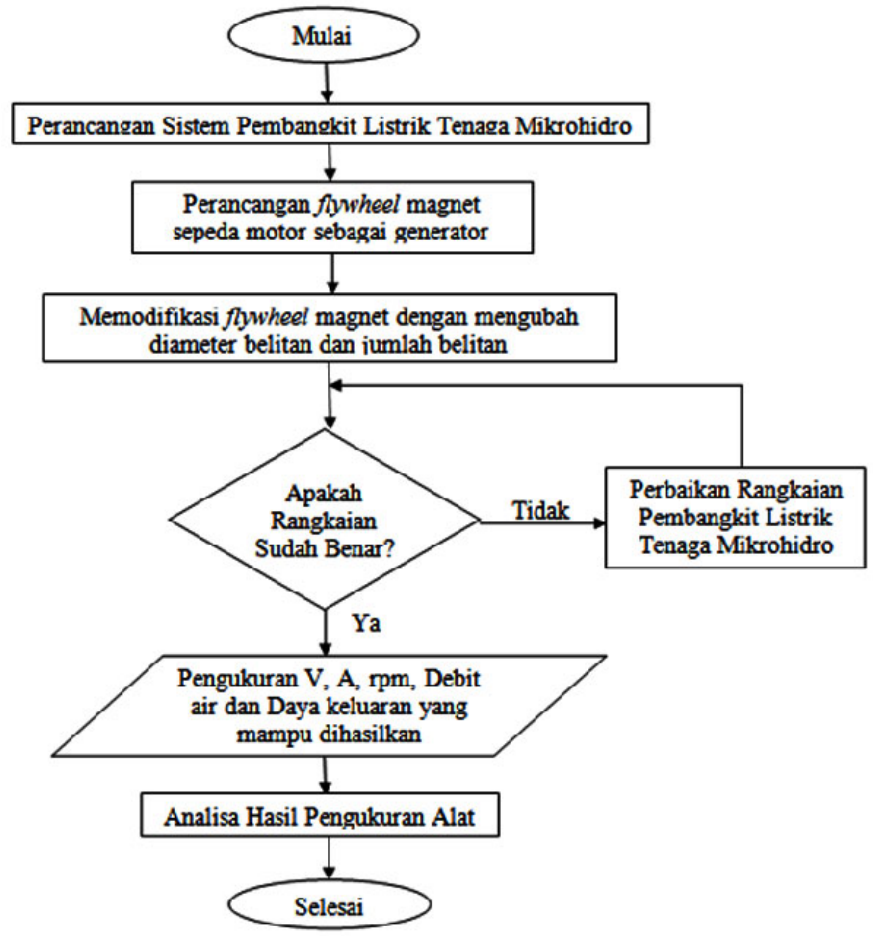

Gambar 2. Flowchart penelitian

\section{Hasil Pengujian dan Pembahasan}

a. Hasil Pengujian

Hasil pengujian flywheel magnet asli dengan kecepatan putar rata-rata $750 \mathrm{rpm}$, menggunakan pipa berdiameter $8,5 \mathrm{~cm}$ dan kecepatan air $3 \mathrm{~m} / \mathrm{s}$, data yang diambil dalam pengujian ini adalah kecepatan putar flywheel magnet, tegangan DC dan arus DC yang dihasilkan oleh flywheel magnet, tegangan AC dan arus AC yang dihasilkan oleh inverter.

Dalam pengujian ini debit air yang mengalir pada pipa dapat diperoleh dengan cara perhitungan sebagai berikut :

Luas penampang pipa : 
$A=\frac{1}{4} \pi D^{2}$

$=1 / 4 \cdot 3,14 \cdot(0,085)^{2}$

$=0,785 \cdot 0,007225$

$=0,0056716 \mathrm{~m}$

Debit air yang mengalir pada pipa :

$Q=A v$

$=0,005672.3$

$=0,017016\left(\mathrm{~m}^{3} / \mathrm{s}\right)$
Hasil pengujian flywheel magnet asli dengan kecepatan putar rata-rata $750 \mathrm{rpm}$, menggunakan pipa berdiameter $8,5 \mathrm{~cm}$ dan kecepatan air $3 \mathrm{~m} / \mathrm{s}$ dapat dilihat di tabel 2 . Sedangkan hasil pengujian flywheel magnet modifikasi dengan kecepatan putar rata-rata flywheel magnet $750 \mathrm{rpm}$, menggunakan pipa berdiameter $8,5 \mathrm{~cm}$ dan kecepatan air $3 \mathrm{~m} / \mathrm{s}$ dapat dilihat pada tabel 3 .

Tabel 2.Hasil pengujian flywheel magnet asli menggunakan pipa berdiameter $8,5 \mathrm{~cm}$ dan kecepatan air $3 \mathrm{~m} / \mathrm{s}$.

\begin{tabular}{|c|c|c|c|c|c|c|}
\hline $\begin{array}{l}\text { Debit air } \\
\left(\mathrm{m}^{3} / \mathrm{s}\right)\end{array}$ & $\begin{array}{l}\text { Putaran } \\
\text { flywheel } \\
\text { magnet } \\
(\mathrm{rpm})\end{array}$ & $\begin{array}{l}\text { Arus AC } \\
\text { (ampere) }\end{array}$ & $\begin{array}{l}\text { Arus DC } \\
\text { (ampere) }\end{array}$ & $\begin{array}{l}\text { Tegangan } \\
\text { AC (volt) }\end{array}$ & $\begin{array}{l}\text { Tegangan } \\
\text { DC (volt) }\end{array}$ & $\begin{array}{l}\text { Beban } \\
\text { lampu } \\
\text { AC } \\
\text { (watt) }\end{array}$ \\
\hline \multirow{4}{*}{0,017016} & \multirow{4}{*}{750} & 0,06 & 0,89 & 185 & 12 & 7 \\
\hline & & 0,06 & 1 & 180 & 10,5 & 15 \\
\hline & & 0,06 & 1,05 & 180 & 11 & 20 \\
\hline & & 0,07 & 1,28 & 190 & 10 & 22 \\
\hline
\end{tabular}

Tabel 3. Hasil pengujian flywheel magnet modifikasi menggunakan pipa berdiameter $8,5 \mathrm{~cm}$ dan kecepatan air $3 \mathrm{~m} / \mathrm{s}$.

\begin{tabular}{lllllll}
\hline $\begin{array}{l}\text { Debit air } \\
\left(\mathrm{m}^{3} / \mathrm{s}\right)\end{array}$ & $\begin{array}{l}\text { Putaran } \\
\text { flywheel } \\
\text { magnet } \\
(\mathrm{rpm})\end{array}$ & $\begin{array}{l}\text { Arus AC } \\
\text { (ampere) }\end{array}$ & $\begin{array}{l}\text { Arus DC } \\
\text { (ampere) }\end{array}$ & $\begin{array}{l}\text { Tegangan } \\
\mathrm{AC}(\text { volt })\end{array}$ & $\begin{array}{l}\text { Tegangan } \\
\mathrm{DC}(\text { volt })\end{array}$ & $\begin{array}{l}\text { Beban } \\
\text { lampu } \\
\mathrm{AC} \\
\text { (watt) }\end{array}$ \\
\hline & & 0,06 & 0,86 & 180 & 11 & 7 \\
0,017016 & 750 & 0,06 & 0,96 & 185 & 10,5 & 15 \\
& & 0,07 & 1,04 & 185 & 11 & 20 \\
& 0,08 & 1,24 & 175 & 10 & 22 \\
\hline
\end{tabular}

Dari tabel 2 dan 3 Arus AC merupakan arus yang keluar dari inverter (setelah inverter), arus DC merupakan arus yang keluar dari flywheel magnet (sebelum masuk ke inverter), tegangan AC merupakan tegangan yang keluar dari inverter (setelah inverter), tegangan DC merupakan tegangan yang keluar dari flywheel magnet (sebelum masuk ke inverter). Beban lampu AC merupakan beban yang terpasang di inverter (setelah inverter).

Hasil dari pengujian flywheel magnet asli dan flywheel magnet modifikasi pada tabel 2 dan tabel 3 dapat juga dilihat pada gambar 3, 4, 5 dan 6 . 


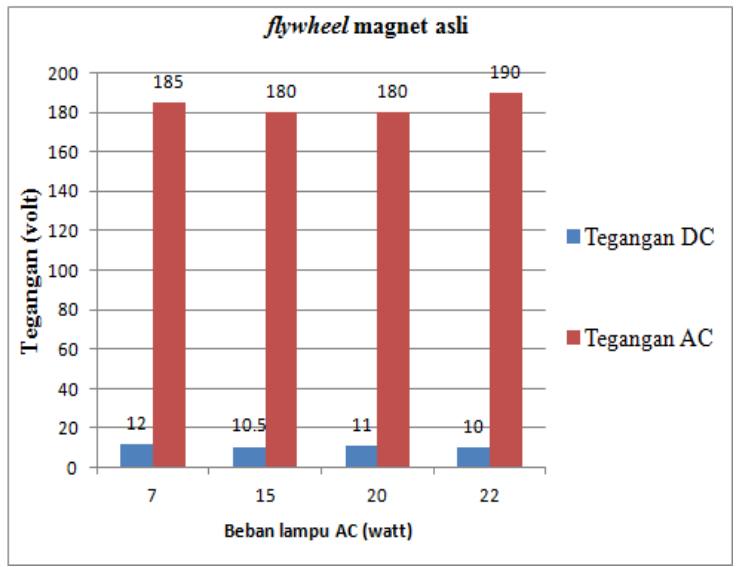

Gambar 3. Diagram tegangan DC dan tegangan AC terhadap beban pada flywheel magnet asli (original)

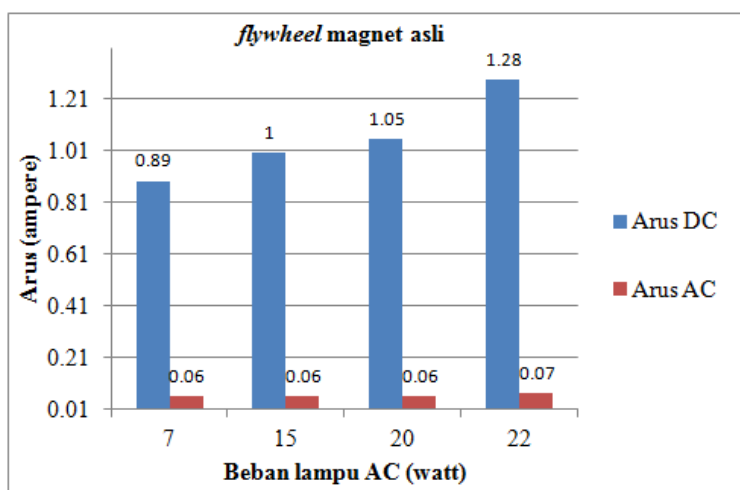

Gambar 4. Diagram arus DC dan arus AC terhadap beban pada flywheel magnet asli

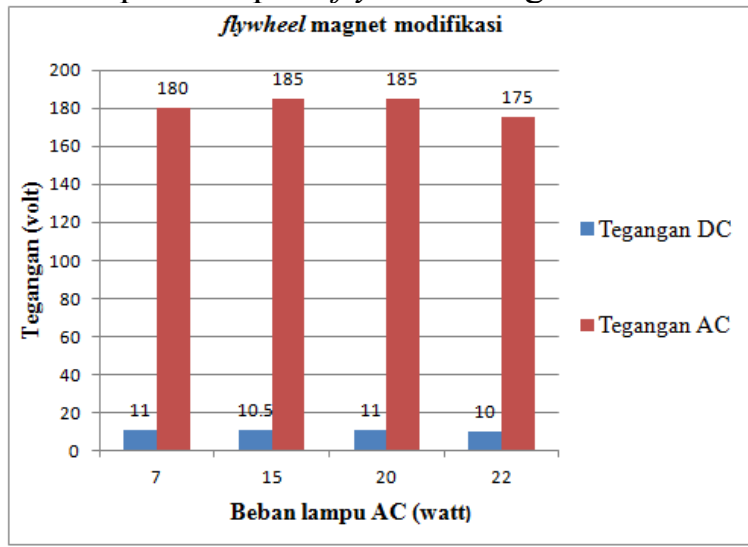

Gambar 5. Diagram tegangan DC dan tegangan AC terhadap beban pada flywheel magnet modifikasi

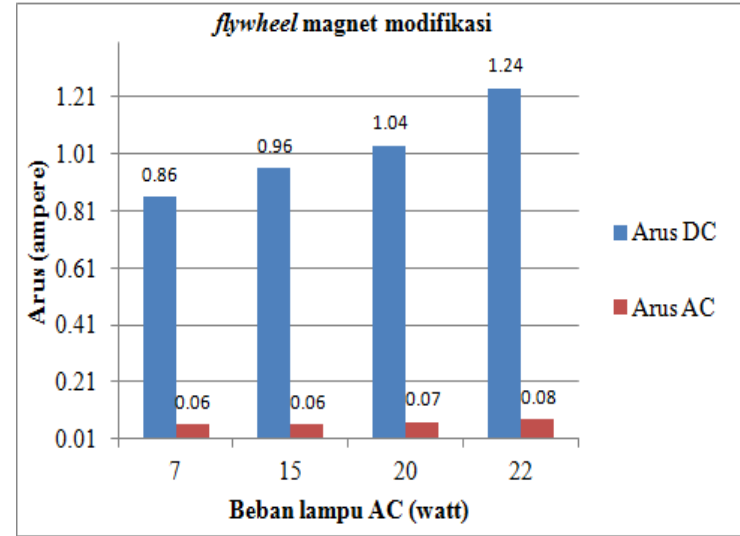

Gambar 6. Diagram arus DC dan arus AC terhadap beban pada flywheel magnet modifikasi

b. Pembahasan Data Pengujian

Pengujian menunjukkan bahwa dengan kecepatan putar rata-rata flywheel magnet $750 \mathrm{rpm}$, flywheel magnet asli dan flywheel magnet modifikasi menghasilkan tegangan $\mathrm{AC}$ dan $\mathrm{DC}$, arus $\mathrm{AC}$ dan $\mathrm{DC}$ dengan beban yang sudah ditentukan. Hasil pengukuran daya yang dihasilkan flywheel magnet dapat dilihat pada tabel 4 dan tabel 5

Daya DC yang dihasilkan oleh flywheel magnet dapat diperoleh dengan cara menghitung sebagai berikut :

- flywheel magnet asli

a. Beban 7 watt

$$
\begin{aligned}
P & =V . I \\
& =12.0,89 \\
& =10,6 \text { watt }
\end{aligned}
$$

b. Beban 15 watt

$$
\begin{aligned}
P & =V . I \\
& =10,5.1 \\
& =10,5 \text { watt }
\end{aligned}
$$

c. Beban 20 watt

$$
\begin{aligned}
P & =V . I \\
& =11.1,05 \\
& =11,5 \mathrm{watt}
\end{aligned}
$$

d. Beban 22 watt

$$
\begin{aligned}
P & =V . I \\
& =10 \cdot 1,28 \\
& =12,8 \text { watt }
\end{aligned}
$$

- flywheel magnet modifikasi

$$
\begin{aligned}
& \text { a. Beban } 7 \text { watt } \\
& P=V . I \\
& =11 \cdot 0,86 \\
& =9,46 \text { watt }
\end{aligned}
$$


b. Beban 15 watt

$$
\begin{aligned}
P & =V . I \\
& =10,5 \cdot 0,96 \\
& =10,08 \text { watt }
\end{aligned}
$$

c. Beban 20 watt

$$
\begin{aligned}
P & =V . I \\
& =11.1,04 \\
& =11,44 \text { watt }
\end{aligned}
$$

d. Beban 22 watt

$$
\begin{aligned}
P & =V . I \\
& =10 \cdot 1,24 \\
& =12,4 \text { watt }
\end{aligned}
$$

Daya AC yang dihasilkan oleh flywheel magnet dapat diperoleh dengan cara menghitung sebagai berikut :

- flywheel magnet asli

a. Beban 7 watt

$$
\begin{aligned}
P & =V \cdot I \cdot \cos \phi \\
& =185 \cdot 0,06 \cdot 0,85 \\
& =9,4 \text { watt }
\end{aligned}
$$

b. Beban 15 watt

$$
\begin{aligned}
P & =V \cdot I \cdot \cos \phi \\
& =180 \cdot 0,06 \cdot 0,85 \\
& =9,18 \text { watt }
\end{aligned}
$$

c. Beban 20 watt

$$
\begin{aligned}
P & =V \cdot I \cdot \cos \phi \\
& =180 \cdot 0,06 \cdot 0,85 \\
& =9,2 \text { watt }
\end{aligned}
$$

d. Beban 22 watt

$$
\begin{aligned}
P & =V \cdot I \cdot \cos \phi \\
& =190 \cdot 0,07 \cdot 0,85 \\
& =11,3 \text { watt }
\end{aligned}
$$

a. Beban 7 watt

$$
\begin{aligned}
P & =V \cdot I \cdot \cos \phi \\
& =180 \cdot 0,06 \cdot 0,85 \\
& =9,18 \text { watt }
\end{aligned}
$$

b. Beban 15 watt

$$
\begin{aligned}
& P=V \cdot I \cdot \cos \phi \\
& =185 \cdot 0,06 \cdot 0,85 \\
& =9,4 \text { watt }
\end{aligned}
$$

c. Beban 20 watt

$$
\begin{aligned}
P & =V \cdot I \cdot \cos \phi \\
& =185 \cdot 0,07 \cdot 0,85 \\
& =11 \text { watt }
\end{aligned}
$$

d. Beban 22 watt

$$
\begin{aligned}
P & =V \cdot I \cdot \cos \phi \\
& =175 \cdot 0,08 \cdot 0,85 \\
& =11,9 \text { watt }
\end{aligned}
$$

Dari tabel 4. Dibawah, arus DC merupakan arus dari flywheel magnet (sebelum masuk ke inverter), tegangan DC merupakan tegangan yang keluar dari flywheel magnet (sebelum masuk ke inverter), daya DC merupakan daya yang diketahui melalui perhitungan menggunakan rumus dan daya tersebut berada sebelum inverter.

Dari tabel 5. Dibawah, arus AC merupakan arus dari flywheel magnet (setelah inverter), tegangan AC merupakan tegangan yang keluar dari flywheel magnet (setelah inverter), daya AC merupakan daya yang diketahui melalui perhitungan menggunakan rumus dan daya tersebut berada setelah inverter.

- flywheel magnet modifikasi

Tabel 4. Hasil pengukuran daya DC flywheel magnet asli dan flywheel magnet modifikasi.

\begin{tabular}{llllll}
\hline $\begin{array}{l}\text { Flywheel } \\
\text { magnet }\end{array}$ & $\begin{array}{l}\text { Arus } \\
\text { (ampere) }\end{array}$ & $\begin{array}{l}\text { Tegangan DC } \\
\text { (volt) }\end{array}$ & $\begin{array}{l}\text { Daya } \\
\text { (watt) }\end{array}$ & $\begin{array}{l}\text { DC } \\
\text { (watt) }\end{array}$ & lampu \\
\hline \multirow{3}{*}{ Asli } & 0,89 & 12 & 10,6 & 7 & \\
(Original) & 1 & 10,5 & 10,5 & 15 & \\
& 1,05 & 11 & 11,5 & 20 & \\
& 1,28 & 10 & 12,8 & 22 & \\
Modifikasi & 0,86 & 11 & 9,46 & 7 & \\
& 0,96 & 10,5 & 10,08 & 15 & \\
& 1,04 & 11 & 11,44 & 20 &
\end{tabular}




\begin{tabular}{llll}
1,24 & 10 & 12,4 & 22 \\
\hline
\end{tabular}

Tabel 5.Hasil pengukuran daya AC flywheel magnet asli flywheel magnet modifikasi

\begin{tabular}{llllll}
\hline $\begin{array}{l}\text { Flywheel } \\
\text { magnet }\end{array}$ & $\begin{array}{l}\text { Arus AC } \\
\text { (ampere) }\end{array}$ & $\begin{array}{l}\text { Tegangan AC } \\
\text { (volt) }\end{array}$ & $\begin{array}{l}\text { Daya } \\
\text { (watt) }\end{array}$ & $\begin{array}{l}\text { AC } \\
\text { (watt) }\end{array}$ & lampu \\
\hline \multirow{3}{*}{ Asli } & 0,06 & 185 & 9,4 & 7 \\
(Original) & 0,06 & 180 & 9,18 & 15 \\
& 0,06 & 180 & 9,2 & 20 \\
& 0,07 & 190 & 11,3 & 22 \\
Modifikasi & 0,06 & 180 & 9,18 & 7 \\
& 0,06 & 185 & 9,4 & 15 \\
& 0,07 & 185 & 11 & 20 \\
\end{tabular}

Hasil pengujian daya DC dan daya AC padac. Pembahasan Potensi Energi Air flywheel magnet asli dan flywheel magnet modifikasi dapat juga dilihat pada gambar 7 dan gambar 8 .

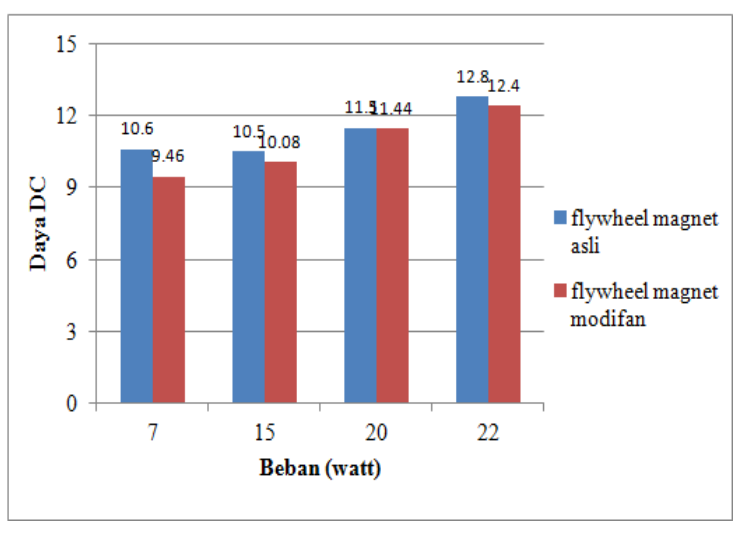

Gambar 7. Diagram perhitungan daya DC terhadap beban pada flywheel magnet asli dan flywheel magnet modifikasi

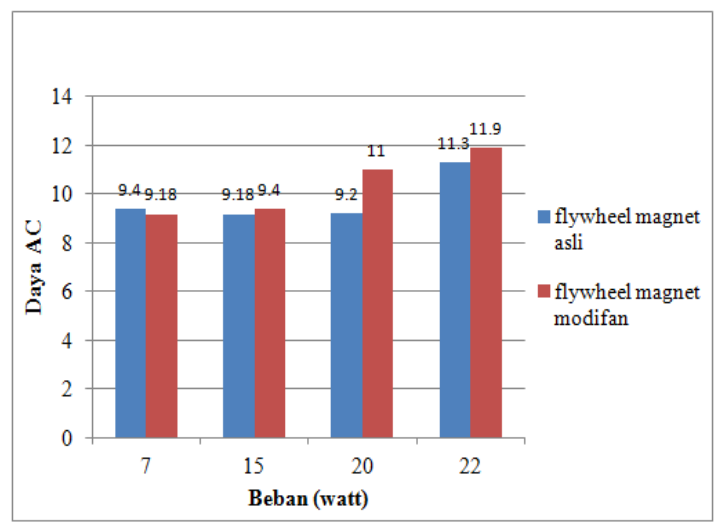

Gambar 8. Diagram batang perhitungan daya AC terhadap beban pada flywheel magnet asli dan flywheel magnet modifikasi.
Daya kincir air yang dihasilkan pada pengujian alat ini dapat dilihat pada tabel 6 . Daya kincir air tersebut diperoleh dengan cara perhitungan dengan menggunakan rumus sebagai berikut :

$P=\rho \cdot g \cdot Q \cdot h \cdot i l t$

$=1000 \cdot 9,81 \cdot(0,017016 \cdot 2.0,8)$

$=9810.0,0272256$

$=267,08314$ watt

Total energi yang tersedia dari suatu penampungan air merupakan energi potensial air yaitu :

$E p=m g h$

Sebelumnya mencari massa air (m) karena belum diketahui

$\rho=\frac{m}{V}$

Perhitungan energi potensial air pada sungai:

$$
\begin{aligned}
& V=p \cdot l \cdot t \\
& =50 \cdot 3 \cdot 0,3 \\
& =45 \mathrm{~m}^{3} \\
& 1000=\frac{m}{45}
\end{aligned}
$$




$$
\begin{aligned}
& m=1000.45 \\
& =45.000 \mathrm{~kg} \\
& E p=m g h \\
& =45000.9,81.2 \\
& =882900 \text { joule } \\
& \text { Perhitungan energi potensial air pa } \\
& V=\left(\frac{1}{4} \pi D^{2}\right) l \\
& =\left(1 / 4 \cdot 3,14 \cdot(8,5)^{2}\right) \cdot 670 \\
& \quad=56,716 \cdot 670 \\
& =37999,88 \mathrm{~cm}^{3} \\
& \quad=0,0379 \mathrm{~m}^{3} \\
& \begin{aligned}
1000= & \frac{m}{0,0379} \\
& =1000 \cdot 0,0379 \\
& =37,9 \mathrm{~kg} \\
E p= & m g h \\
& =37,9 \cdot 9,81.2 \\
& =743,6 \text { joule }
\end{aligned}
\end{aligned}
$$$$
\text { Perhitungan energi potensial air pada pipa : }
$$

Total energi yang tersedia dari suatu penampungan air merupakan energi potensial air.

Perhitungan energi kinetik air pada sungai :

$$
\begin{aligned}
& E k=\frac{1}{2} m v^{2} \\
& =1 / 2.45000 .(3)^{2} \\
& =22500.9=202500 \text { joule }
\end{aligned}
$$

Perhitungan energi kinetik air pada pipa :

$$
\begin{aligned}
E k & =\frac{1}{2} m v^{2} \\
& =1 / 2 \cdot 37,9 \cdot(3)^{2} \\
& =18,95 \cdot 9 \\
& =170,55 \text { joule }
\end{aligned}
$$

\section{Kesimpulan}

Berdasarkan penelitian dan analisa pemanfaatan aliran sungai Waduk Botok untuk Pembangkit Listrik Tenaga Mikrohidro menggunakan kincir air tipe overshot di Waduk Botok, Mojodoyong, Kedawung, Sragen, Jawa Tengah. Hasil pengujian menunjukkan bahwa daya DC yang dihasilkan flywheel magnet asli saat dipasang beban lampu maksimal 22 watt menghasilkan daya DC sebesar 12,8 watt dan flywheel magnet modifikasi saat dipasang beban lampu maksimal 22 watt menghasilkan daya DC sebesar 12,4 watt, sedangkan daya AC yang dihasilkan flywheel magnet asli saat dipasang beban lampu maksimal 22 watt menghasilkan daya AC sebesar 11,3 watt, dan flywheel magnet modifikasi saat dipasang beban lampu maksimal 22 watt menghasilkan daya AC sebesar 11,9 watt.

\section{DAFTAR PUSTAKA}

Budiman, Aris. Asy'ari, Hasyim. Hakim, Arif Rahman. Desain Generator Magnet Permanen Untuk Sepeda Listrik. Jurnal Teknik Elektro Fakultas Teknik UMS, Vol. 12 No. 01 ISSN 1411-8890.

Damastuti, Anya P. 1997. Pembangkit Listrik Tenaga Mikrohidro. Sumber: http://www.elsppat.or.id/download/file/w8 a6.pdf

Djajusman Hadi, S.Sos. M.AB dan Budiharto, S.Pd. 1998. Artikel kincir air kaki angsa dan inovasi listrik Mikrohidro

Sumber: http://www.kendali.net/

Jalius, Jama. Dkk. 2008. Teknik Sepeda Motor Jilid 1 Untuk Sekolah Menengah Kejuruan. Jakarta.

Marsudi, Djiteng. 2011. Pembangkitan Energi Listrik Edisi Kedua. Jakarta: Erlangga.

Paryatmo, Wibowo. 2007. Turbin Air. Yogyakarta: Graha Ilmu 